\title{
7
}

\section{Ontology and Reason Giving in Law}

\author{
KENNETH M EHRENBERG ${ }^{*}$
}

John Gardner has noted that legal positivism is more a theory of legal validity than it is a theory about law's nature. ${ }^{1}$ This is true in that one can be a legal positivist and hold a variety of different theories about law's nature, but not to the extent that 'anything goes' ontologically speaking. Rather, it seems fairly difficult to be a legal positivist and not say that the law is a kind of social fact.

That being said, however, there are a variety of ways of creating social facts so there is some room for disagreement when it comes to the nature of law within the wide umbrella of legal positivism. If our focus is legal validity, then we may not have too much reason to wade into these deeper metaphysical waters. However, I believe that legal positivism has a challenge that is not (as) present in other theories of law: the problem of explaining law's normativity. I contend that one of the best hopes for meeting this challenge is to be found in getting more clarity about what it is that yields these special social facts, although I remain open to the possibility that the challenge can also be met in other ways.

Let us first get a bit more clarity on the challenge itself, then we will see how settling the metaphysical questions about law can help to meet the challenge, and then I can suggest how my preferred answer to the metaphysical questions meets the challenge.

\section{Hume's Guillotine}

The challenge is a version of the age-old problem identified perhaps most clearly by David Hume: that one cannot reason from a set of merely descriptive factual premises to a conclusion that contains a normative claim..$^{2}$ If we accept that law is

\footnotetext{
* Assistant Professor of Philosophy, Adjunct Professor of Law, University of Alabama. Some of the ideas here get further development in The Functions of Law (Oxford, 2016).

1 See Gardner (2012: 33).

2 See Hume (1739: bk III, Pt|1, s 1).
} 
a social fact, then it would seem to be a descriptive fact without a clear normative implication. Consider the following argument:

P1. Some guys in Washington, DC, back in 1954 wrote a lengthy document some part of which contained a clause specifying that citizens and residents of the United States file and pay their taxes by 15 April of each year.

P2. When asked to show their assent to this document, a majority of people in the room at the time said 'aye'. This happened twice, once on each side of the building.

P3. This document was then sent up the street where another guy signed it.

$\therefore$ I [as a US citizen] ought to file and pay taxes by 15 April of each year.

Before we get into the details of this argument and how to tighten it up a bit, we should notice one thing about the obvious gap and what Hume was saying. We need not conclude that the normative conclusion is incapable of having a truthvalue merely because one is not entitled to draw it from non-normative facts. Hume's point was merely that normative conclusions (which might still be true or false, unless one accepts a meta-normative theory denying this) are of a different kind from non-normative facts. Hence, one cannot reason from the nonnormative to the normative. There are no 'oughts', 'shoulds' or other analogues in the premises, so we cannot soundly offer a conclusion that contains one.

The problem we will tackle here is therefore not how to justify a given normative conclusion from merely descriptive premises about the law, but how we are even entitled to expect such a justification. In other words, the problem is what makes a robust normative conclusion truth-apt, given an argument that apparently only has descriptive premises. Put another way, we can see Hume's point as saying that there is a category mistake in reasoning from merely descriptive premises to a normative conclusion: even if the normative conclusion can have a truthvalue, the kind of truth it contains is different than the kind of truth contained in the premises. Hence one cannot reason from descriptive kinds of premises to normative kinds of conclusions. So our task is not here to justify that one ought or ought not to follow the law. Rather, we are trying to discover how it is even possible for such conclusions to be of the right kind given the apparently merely descriptive premises. To do so we must deny that there is a Humean category mistake in such arguments about the law. And to support that denial we must investigate the metaphysics of the law to show where normativity creeps into the otherwise merely descriptive premises.

\section{Getting to a Legal 'Ought'}

Now clearly, before we can even begin to examine this argument as an instance of legal reasoning, we must get the idea of law into the argument somehow. The descriptions in the three premises are non-legal descriptions of events that have 
legal consequences within a system of law already in place. So a more precise option would be to set out the descriptions of prior events that make it the case that these events specify a legal outcome. We would have to say that there was a foundational document adopted by the original State legislatures, specifying the composition and procedures of the bodies on the two sides of that building; that the guys saying 'aye' on each side of the building were themselves picked out by a selection procedure in each State consistent with the foundational documents of those States and of the over-arching foundational document adopted by the original States; that the guy up the street signing the document was himself picked out by a selection procedure specified within that foundational document; that the content of the document to which they were saying 'aye' was itself consistent with the foundational document adopted by the original States, etc. But for ease of treatment let us boil all this down and just add a fourth premise:

P4. These events constituted a law in the United States.

The status of this particular premise is somewhat more opaque, especially as it deploys the very concept that we are primarily worried about, LAW. But the point of this exercise is to inquire into the propriety of reaching a normative conclusion from legal premises, so it will have to be in there somehow. We will also shortly see that the question of whether this premise is entirely non-normative is precisely what separates legal positivists from the anti-positivists. We might also be wondering a bit about this 'constituted' relation, a point we will return to a bit later.

First, however, let us get something more explicitly normative into our argument:

P5. Legally, I ought to pay my taxes by 15 April of each year.

I say that this is explicitly normative because it uses an 'ought' term, but that normativity might be misleading or of the wrong kind to justify the more basic conclusion that I ought to pay my taxes by 15 April of each year. Instead, this is a contextually bound claim that may or may not have more basic normative consequences. So while there is an 'ought' in the statement, it may not get us where we need to be. According to legal positivism, a legal requirement is still a matter of descriptive fact about the legal system even if it is a conclusion of the social fact premises.

To be more precise, there is some dispute among legal positivists about whether legal normativity is a special context-dependent form of normativity, or if it represents instead a kind of assertion about our moral obligations. HLA Hart held the first view and Joseph Raz holds the second. ${ }^{3}$ Under Hart's view, the Humean problem is avoided by stipulation. That is, instead of the conclusion we are discussing here, we simply stick 'legally' in front of it, thereby substituting P5 for the conclusion, and our work is done. We are entitled to the new conclusion because, while it uses normative terminology, its truth is merely a matter of the descriptive facts that came before. What one legally ought to do is entirely exhausted by the social

\footnotetext{
3 See Hart (1982: 159-60); also Raz (1984: 123, 130-31). See also Himma (2013: 16, 18-19).
} 
facts that determine the law: if the law says to pay your taxes by 15 April, then that is what one legally ought to do. What one ought to do tout court is simply not at issue until we get into a wider theory of political obligation. Law's normativity is therefore artificial in both senses of the word.

While that is certainly one way out of this particular conundrum, I'll follow Raz's view because of the interesting problem that it leaves open: how to justify the move from mere descriptive facts to a robust normative conclusion. ${ }^{4}$ That is, the 'legally' qualifier, places the normative claim in a special context such that it becomes a descriptive fact about the legal system in question and not a normative claim about what I ought to do. So we still need an argument to strip the 'legally' qualifier from the normative statement. Under this view we can either see P5 as an additional premise on its own, or as a nested conclusion reached from the prior premises but still antecedent to the more basic normative claim made in the main conclusion.

\section{Need for a Metaphysical Answer}

Anti-positivists such as natural lawyers have another easy way out of the problem. Natural law can be understood to add two premises:

NLP1. Law is an ordinance of reason. ${ }^{5}$

NLP2. One should do what the balance of reasons dictates.

So we have a normative claim squarely in the premises. If we are comfortable with the additional premise that this particular law is not overly defective (in that it is not against the balance of reasons), we can get a decent argument for the conclusion. But we have to be satisfied with the premise that law is an ordinance of reason, linking practical reason to the non-defectiveness conditions of law itself. That is one metaphysical claim about the nature of law: that it is an ordinance of reason. And it is one way to offer a kind of solution to the problem. So in natural law we already find a metaphysical solution to the problem, just not one that legal positivists are comfortable accepting. If we aren't comfortable with that particular metaphysical claim, believing instead perhaps that legality is entirely a creation of human beings and therefore exhausted by the social facts described in the original premises, then we still have to figure out some way of getting from 'it's a law' and 'legally, I ought to pay' to 'I ought to pay'.

Now it may also be that the argument simply doesn't go through. There are certainly circumstances in which I ought not to pay. The question isn't what forces

\footnotetext{
${ }^{4}$ Raz himself answers this by specifying the legitimacy conditions for authority, seeing law as a paradigm case (although frequently illegitimate) of that authority. I'm trying to specify what kind of thing law must be in order for it to be possibly legitimately authoritative. The Hartian answer itself only pushes this problem back one step anyway.

5 See Aquinas (1993: I-Ii; Qq=90-97).
} 
the truth of the conclusion unerringly, but rather what in the premises makes the conclusion truth-apt given that the nature of those facts is different in kind than the normative claim of the conclusion. The answer is to find normativity lurking elsewhere in the premises within the nature of law. That is, in an understanding of how those facts constitute law we will see the beginnings of a normative demand.

If the goal, as just stated, is to discover what makes the conclusion truth-apt, given the premises as originally conceived do not have any obviously normative contents, then to reach the goal there would have to be something within those contents that hid some aspect of normativity. There would have to be something in the nature of the things referred to in the premises that would allow for normative conclusions to be drawn from facts about them. And here is the first suggestion that the solution must be metaphysical. If we are looking at the nature of the things described in the premises for our lurking normativity, we are asking for a more complete picture of the ontology of some aspect of what we are talking about. In the original premises $\mathrm{P} 1-\mathrm{P} 3$, the descriptions were fairly straightforward, although there might be some questions about 'United States', 'taxes' and 'assent'. But the really opaque part is in P4. We need to have greater clarity of what it is for a set of facts such as shown in P1-P3 to 'constitute a law', as that is most likely the source of normativity that makes the original conclusion truth-apt.

Let me be clear about something else. In accepting Raz's picture of the nature of the normative demand that law makes, one might think that we can just follow Raz's picture of authority generally and say that what legitimates the normative demand that law makes is whether it provides a better guide to the balance of reasons that apply to us than we would be able to discover and/or follow on our own. ${ }^{6}$ I am not adverse to this idea of authority but I need to make it clear that it is not quite the project that we set out on here. Raz has given us an analysis of what legitimates authority generally and then shows how that analysis can be applied to law. ${ }^{7}$ The result is a picture of what conditions law would have to satisfy in order for its directives to be legitimate. That might at first blush appear to be a perfectly adequate answer to the task of validating the argument set out above. But further investigation, we should see that it is not quite the same argument. Instead, we would have given an argument with a conclusion about when we should follow a legitimate authority and then perhaps given some premises about when legal directives meet those conditions for legitimate authority.

Now it very well may be in the end that the only time we really should follow a legal directive is when it meets the conditions for legitimate authority. So maybe the only argument we should really be concerned with is the one over what legitimates an authoritative directive and how those conditions might be applied to law. But for better or worse, the task we have set ourselves above is what about the law itself makes a normative conclusion truth-apt, based on merely descriptive premises about the law. So the question is then what is it in the nature of the law

\footnotetext{
6 See Raz (1986: 53). See also Ehrenberg (2011: 884, 886).

7 See Raz (1989: 1153, 1184). See also Ehrenberg (2011: 886).
} 
that allows us even to entertain the propriety of reasoning from descriptive premises to a normative conclusion. Raz takes it as given that law could be legitimately authoritative (seeing it as a paradigm instance of authority). ${ }^{8}$ Our question here is what it is about law that makes it so.

Remembering what exercised Hume about the is-ought problem also helps to see why the solution must be a metaphysical one. The question is not merely how we can know the truth of a normative conclusion where the premises are merely descriptive. Rather the question is how a truth of a different, normative, kind could be derived from merely descriptive premises. This calls for an investigation either into the nature of normativity generally, or (at least) one into the nature of the particular descriptive premises that supposedly ground the normative conclusion. So let us now turn to thinking a bit more about the relation between the descriptions in $\mathrm{P} 1-\mathrm{P} 3$ and $\mathrm{P} 4$.

\section{An Artefact}

$\mathrm{P} 1-\mathrm{P} 3$ are descriptions of actions taken by a set of individuals over time. $\mathrm{P} 4$ is a claim that these actions are to be understood as having created something that wasn't in existence before those actions (or to have altered some aspect of what was there before). Given that the actions involved writing things down, showing assent to what was written, and then adding one's name to the writing (we assume, after that person has read it), it does not seem too much of a stretch to say that these actions were intentional on the part of those who participated (or at least the vast majority of them).

Some acts could be either intentional or non-intentional. I can decide to take a breath at a certain point in time, making an action that is usually not intentional into one that is intentional. It is also certainly true that not all human intentional action is necessarily goal-directed. I can intentionally start doodling on a pad of paper without having any goal in mind about the picture I am trying to create. However, I would also say that the more interactive and collaborative an action is with others, the more it would appear necessary for it to be goal-directed. After all, if I am hoping that others will participate in the action with me, they will likely need reasons to do so. Their reasons might not be the same as mine. Indeed, everyone might participate with his or her own individual reason for doing so. But to say that it is interactive and collaborative is to say that the people participating likely share some conception of what it is that they are doing together. So, while their motivating reasons might be vastly different from one another, their understanding of the enterprise itself is likely to have some unified goal insofar as they understand with one another what it is that they are doing together.

\footnotetext{
8 See Raz (1985: 295, 302).
} 
Given the descriptions we have in $\mathrm{P} 1-\mathrm{P} 3$, and the more complex description in $\mathrm{P} 4$, along with the idea that the people referred to are doing something together, it is not unreasonable to say that they are acting together in order to constitute the law as described in P4. (And if you do find this to be too much of a jump, I'm happy to include it as an additional premise - that the participants described in P1-P3 understood what they were doing was creating a law and acted in order to do that. After all, that addition is still clearly descriptive.) While to the extent that they are working together might suggest that they are merely engaging in some group activity (which they certainly are), the idea that their group activity is constituting something as described in P4 suggests that their activity is not merely goal-directed but productive. That is, their activity is changing or creating something.

Here I will help myself to a taxonomy first articulated (to my knowledge) by my former colleague Randall Dipert. Any materials the people in Washington used toward their goals could be called 'instruments'. Materials that were specially adapted to serve their goals would be 'tools', while materials that were specially adapted to serve specific goals and to communicate that usage would be understood as 'artefacts.' ${ }^{9}$ (Tools are a subcategory of instruments and artefacts are a subcategory of tools.) If I pick up a rock from the ground and use it to smash open some nuts, I'm using the rock as an instrument. If I bang off some flakes of the rock to give it a smoother surface for better smashing those nuts, I've made a tool. And if I attach to it a handle and perhaps design special ridges specifically adapted to nut-cracking, then I've made an artefact. ${ }^{10}$

Notice that one can recognise an artefact without knowing what precise usage it is meant to serve. However, the primary way we try to understand an artefact with which we are unfamiliar is by trying to discover what it is (or was) used for.

When these guys in Washington wrote something down on paper, polled their members for their assent (twice) and then sent the writing up the street for another guy to sign, each person was clearly acting with the intent that what they were doing would be understood as the creation of something with normative implications. They wanted us to pay our taxes by 15 April each year and they thought that what they were doing would have the effect (among others) of creating a norm that we do so. Hence, what they were doing was creating a kind of tool that (they imagined) established a norm that United States residents pay their taxes by 15 April each year. But more than merely a tool, what they created also carried the signal to them and others that they thereby created that norm. Hence they created a kind of artefact, one function of which was to establish the norm that US residents pay their taxes by 15 April of each year.

However, the fact that they created an artefact with the function of establishing this norm does not entail that the norm was successfully established. It is, of course,

\footnotetext{
9 See Dipert (1995: 119, 121-29). Note that the intended audience for the communication by an artefact can be quite circumscribed.

10 There are obviously serious problems with individuating the particular goals that a designer might have in mind in making an artefact, but that need not worry us for the moment.
} 
entirely possible to create an artefact with a function that cannot be fulfilled. I can create a perpetual motion machine, which will always be doomed to failure. Many smart people created machines the function of which was to fly before the Wright brothers finally made a successful one. ${ }^{11}$

Yet, even if the particular norm that they wanted to create wasn't thereby created, if they were successful in creating an artefact at all, then some normativity is thereby entailed by the fact of artefact creation. Amie Thomasson tells us that public artefacts (artefacts that are designed to be recognisable to people other than merely the creator) have 'receptive' features that signal how the object is to be used or treated. ${ }^{12}$ It is therefore this signalling feature of such artefacts that introduces the barest form of normativity into the otherwise completely descriptive account of what is going on. In the case of law, the norm being signalled generally may be simply that the norm putatively created by the legislation is being singled out for a special kind of social emphasis.

Once again, even these barest norms of treatment conveyed by the signalling need not be normatively dispositive for action. One can have over-riding reasons to ignore the signals conveyed by the artefact. I can use the nut-cracker as a doorstop, and I can see some laws as a reasons for disobedience rather than reasons for compliance. Yet in each of these cases, my mere usage of these artefacts in other ways than those they were intended does not mean I stop recognising them as the kind of artefacts they are. My nut-cracker remains a nut-cracker, even when used as a doorstop. The point was to show where and how normativity can arise within the otherwise descriptive claims in the premises of the argument, to show how the conclusion can be truth-apt even when based on descriptive premises.

This signalling is precisely what opens up the possibility that the normativity created in making the artefact applies more broadly beyond those who are directly involved in its creation. Even theorists who are doubtful that law can create new norms beyond merely activating pre-existing conditional norms, such as David Enoch, accept that norms can be created through the communication of an intention to do so (such as me making a request of you, which communicates my intention that you see the request as a reason for complying with it). ${ }^{13}$ So if law is a public artefact and public artefacts consist (partially) in signalling that they be received by others as carrying normativity, then that signalling can be seen as the communicated intention to create a norm, at least of recognition.

The implication here is that the most basic norm created when the artefact is created is that the artefact is one token of a type understood (here) in terms of the function the artefact is to perform. This is why the nut-cracker doesn't stop being a nut-cracker when used as a doorstop. And I can understand that the point of the

11 There might be some debate about whether an artefact can have a function that it is doomed never to fulfil. But I leave this aside for now as clearly the artefact's creators can intend for it to serve that function, which is generally enough to consider it an artefact.

12 See Thomasson (2013: 49).

13 See Enoch (2011: 12-13). 
behaviour of these guys in Washington is to put some special emphasis on a norm to pay taxes by 15 April, even if I never comply.

\section{An Institution}

Now, even if you think that this might get us somewhere in the explanation of where normativity arises in our otherwise merely descriptive premises, you might be somewhat bothered by what appears to be a kind of circularity in this picture of the nature of law. That is, the intention communicated by the behaviour of the guys in Washington is that I treat the result of their actions as a law-that is what is meant by that special social emphasis. The nut-cracker is still a nut-cracker even when repurposed; the law is still a law, even when broken. But that means these actions creating the artefact, constituting the law, are somehow self-defining. Normativity may have been created, but only by allowing of this bootstrapping self-definition.

Put another way, there appears to be an important distinction between the law and the nut-cracker. To create a nut-cracker, one must merely create an object with the purpose and structural ability to crack nuts, and which signals its usability for doing so. But to create a law, one follows a set of procedures that earlier people set forth for doing so (in more law that was pre-existing or that they created), thereby giving the status of law to what one does. The key to the law is its status and that status and its implications seem to have been created at some point out of nothing.

The answer to this final problem lies in understanding the nature of an institution and how it creates and defines a special status. The law isn't just any artefact, but rather is a specific kind of artefact: an institution. The special task of institutions is to create and alter 'desire-independent reasons for action. ${ }^{14}$ So the truth-aptness of a normative conclusion stemming from merely descriptive premises lies in whether those premises are describing the creation of an artefact generally, or the activation/creation of an institution specifically.

As kinds of artefacts, but unlike other social forms like rituals or cultures, institutions are also self-consciously created. As a certain kind of public artefact for manipulating norms, institutions are intentionally created social arrangements for pursuing certain ends by altering the normative relationship among those who are within or subject to the institution.

Following John Searle's influential theory of institutions, institutional facts are social facts about 'status functions' that are assigned to objects, people, events, practices, etc by a specific group adopting a 'constitutive rule. ${ }^{15}$ Those statuses are

\footnotetext{
14 See Searle (2010: 23, 99).

15 ibid 23-26, 40-45. The notion of 'function' in 'status function' is akin to the mathematical notion and should not be confused with the notion relevant for understanding artefacts more generally.
} 
understood to alter the normative relations among people in order to serve the purposes of those creating or using the institution.

But the point of introducing institutions to this discussion for our purposes here is to try to answer the apparent problem of the self-defining nature of law's special normative status. While physical artefacts like nut-crackers get their little bit of normativity from the intentions their creators have for them to serve and signal their particular functions, our guys in Washington are simply writing things down, saying 'aye', and signing their names. And that's supposed to put a specific kind of special status on what they've done, giving us reasons for action.

For this final piece of the puzzle, we must return to where we started at the very beginning: legal validity. On the first page I made much of the distinction between the metaphysics of law and legal validity, pointing out that legal positivists can disagree on the metaphysics of law while agreeing on a theory of legal validity. But in order to give a metaphysical explanation of how normativity arises in law, I need to show where legal validity arises in my metaphysical picture since legal validity determines the contours of the normativity of law.

To do this, I am going to help myself to another distinction made by Searle in his theory of institutions. Searle distinguishes between informal institutions and formal institutions. In the former, the special normative statuses (conveying 'deontic powers' to participants) are doled out case by case. ${ }^{16}$ That is, there are no formal rules for determining what counts as an instance of an informal institution. So those participating in that social arrangement must establish whether they are participating in an instance of the arrangement and the special rights, powers and responsibilities entailed by it in each case. Cocktail parties are informal institutions in that each one must be understood as such, token by token. ${ }^{17}$

In formal institutions, however, the constitutive rule is 'codified', specifying what features an instance must have to be counted as one of that type of institution. ${ }^{18}$ This notion of codification is Searle's and is meant to be broader than the legal usage. But the idea is that by codifying a constitutive rule for the institution, we are giving specifications of what instances, actions, roles, enactments, writings, etc are normatively valid by the institution's own lights. Codification is a formalised process of declaration for attaching, creating or altering normatively laden statuses.

Strictly speaking, the formal/informal distinction among institutions isn't entirely necessary to solve the self-referentiality problem, but it helps to understand what is going on in arguments about law's normativity. Recall that the selfreferentiality problem arose because an institution defines its own statuses. To be a nut-cracker is to be designed and manufactured in such a way as to be primarily purposed to crack nuts and to signal that usage. To be a cocktail party is to be treated as a cocktail party by participants, whatever that treatment might be for

\footnotetext{
16 ibid 91.

17 See Searle (1995: 87-88).

18 ibid 5.
} 
them. To be a law is to be created as a law, where the powers conveyed by being a law are set forth in further laws that determine which laws count as such. The two institutional cases display self-referentiality in that they are constituted by statuses that are self-defined: To be a cocktail party is to be treated as a cocktail party. To be a law is to be created as a law. But in these institutional cases the status named by (or of) the institution ('law', 'cocktail party') is merely a 'placeholder for the linguistic articulation of all [the] practices' that perform the function(s) that the status is supposed to accomplish. ${ }^{19}$ The self-definition of these statuses is not a problem precisely because the name of the status is simply standing in for the normative alterations that are supposed to be effected by the creation of the institution or the application of the institution to a new instance. When it happens formally, as it does in legal situations, the processes and normative implications of that status are set out in prior formal rules that must be followed for new instances to be institutionally recognised.

So we now have a more complete picture of how the metaphysics of law answers the problem of explaining law's normativity when we understand law to be a species of social fact. The mere descriptive facts of what some people do in Washington have normative implications because those people are 'officials' within legal institutions, their statuses and thus their deontic powers specified and defined by those institutions. When they act in their official capacities, they are making changes to those institutions, which then has normative implications for those subject to those institutions.

While it will always be a separate question whether people supposedly subject to those institutions should pay any attention to how its officials claim to alter their normative space, what gets them into the zone of danger for such a normative change is that institutions are kinds of artefacts (albeit abstract ones). As such they are special kinds of tools that signal their functionality to those who interact with them. That signalling carries at least the basic normative demand that we recognise the artefact for what it is in terms of what it is supposed to do. In this case, the function of the artefact is itself to create and alter norms.

There are two kinds of normativity at play here. Seeing law as a kind of artefact bundles the most basic kind of normativity into the otherwise descriptive picture. That is, a norm formed by the communicated intention of the artefact creator that we see the creation as a member of a specific kind. In this case, it is merely that we recognise what those guys in Washington did in 1954 was to create a law, even if we eventually decide not to follow it. We can decide not to use our nut-cracker to crack nuts (or even use it as a doorstop), yet we don't stop understanding it to be a nutcracker. So even if we decide not to follow the law, we still recognise it as a law and that it was supposed to alter our rights and responsibilities. This is what makes it possible to draw normative conclusions from otherwise descriptive premises. The communicated intention of the artefact creator is a normative demand bundled with those premises.

19 ibid 52-53. 
The other kind of normativity is the particular demands of the law itself, understood as an instance of a formal institution. Within the institutional ambit, those norms are binding insofar as they are valid. Whether those norms are robustly binding in a wider sense depends on whether those addressed by the norms have good reasons to be bound by the institution and what it is doing. That is the particular question of whether one should follow that law and depends for its answer on whatever justifies the law's authority on that point.

So what we add with $\mathrm{P} 4$, that the actions undertaken by those guys in Washington constituted a law, is a norm that we recognise what they did as law and as potentially having normative implications for everyone described within the ambit of that institution. This doesn't entitle us to say that the argument is valid in that the conclusion could still be false even when the premises are true. But it does explain why that normative conclusion could possibly be true even though the premises are otherwise merely descriptive.

\section{References}

Aquinas, T (1993) Saint Thomas Aquinas, the Treatise on Law/(Notre Dame, IN, University of Notre Dame Press)

Dipert, RR (1995) 'Some Issues in the Theory of Artifacts: Defining "Artifact" and Related Notions' 78 Monist 119

Ehrenberg, KM (2011) 'Joseph Raz's Theory of Authority' 6 Philosophy Compass 884

Enoch, D (2011) 'Reason-Giving and the Law' in L Green and B Leiter (eds), Oxford Studies in Philosophy of Law (Oxford, Oxford University Press) vol 1

Gardner, J (2012) Law as a Leap of Faith (Oxford, Oxford University Press)

Hart, HLA (1982) Essays on Bentham: Jurisprudence and Political Theory (Oxford, Clarendon Press)

Himma, KE (2013) 'The Ties that Bind: An Analysis of the Concept of Obligation' 26 Ratio Juris 16

Hume, D (1739) Treatise of Human Nature (London, printed for John Noone)

Raz, J (1984) 'Hart on Moral Rights and Legal Duties' (1984) 4 Oxford Journal of Legal Studies 123

_ (1985) 'Authority, Law and Morality' 68 Monist 295

_ (1986) The Morality of Freedom (Oxford, Clarendon Press) (1989) 'Facing Up: A Reply' 62 Southern California Law Review 1153

Searle, JR (1995) The Construction of Social Reality (New York, Free Press)

— (2010) Making the Social World: The Structure of Human Civilization (Oxford, Oxford University Press)

Thomasson, AL (2013) 'Public Artifacts, Intentions and Norms' in M Franssen et al (eds), Artefact Kinds: Ontology and the Human-Made World (New York, Springer) 